\title{
A Finite-State Parser for Use in Speech Recognition
}

\author{
Kenneth W. Church \\ NE43-307 \\ Massachusetts Institutc of Technology \\ Cambridge, M^. 02139
}

This paper is divided into two parts. ${ }^{1}$ The first section motivates the application of finite-state parsing techniques ac the phonctic level in order to exploit certain classes of cuntextual constraints. - In the second section, the parsing framework is extended in order to account for 'feature spreading' (e.g., agreement and co-articulation) in a natural way.

\section{Parsing at the Phonetic Level}

It is well known that phonemes have different acoustic/phonetic realizations depending on the context. Fur example, the phoneme $/ U$ is typicaily realized with a different allophone (phonetic variant) in syllable initial position than in syllabic final position. In syllabie initial position (e.g., Tom), $/ U$ is almost always reicased (with a strong burst of energy) and aspirated (with h-likc noise), whereas in syllable final position (c.g., cat). / $t /$ is uften unrelcased and unaspirated. It is common practice in spech research to distinguish acoustic/phonetic propertics that vary a great deal with context (e.g., release and aspiration) from those that are relatively invariant to context (e.g., place, manner and voicing). ${ }^{2}$ In the past, the emphasis has been on invariants; allophonic variation is traditionally secn as problematic for recognition.

(1) "In most systems for sentence recognition, such modifications must be vicwed as a kind of 'noise' that makes it more difficult to hypothesize lexical candidates given an input phonetic transcription. To see that this must be the casc, we note that each phonological rule [in an example to be prescnted below]

\footnotetext{
1. This rescarch was supponed (in par) by the Nationa! Institutes of Ilealth Grant No. I MII $M$ 03374-01 and 03374-02 from the National Library of Medicine.

2. Place refers to the location of the constraction in the rocal tract. Examples include:

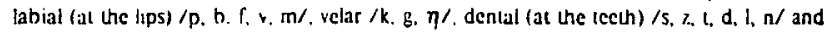
pataul $/ s, i . j, j$, Wanner distunguishes among vowels. liquids and glides (e.g., $/, r, y$, w/). (ricalives (e.g., /s, z. r, v/), nasals (c.g., /n. m. $\eta /$ ) and slops (c.g., /p, t, k, b. d. g/) voicing (perindic vibration of the vocal folds) distingusshes sounds like $/ b, d . g /$ from sounds like $/ p, L$ V.
}

results in irreversible ambiguity - the phonological rule does not have a unique inverse that could be used to recover the underlying phonemic icpresentation for a lexical item. For cxample, ... schwa vowels could be the first vowel in a word like 'about' or the surface rcalization of almost any English yowel appearing in a sufficiently destressed word. The conguc hap [C] could have come from a $/ \mathrm{t} /$ or a $/ \mathrm{d} / . "$ Klatt (MlT) [21, pp. 548-549]

This view of allophonic variation is representative of much of the speech recognition litcrature, especially during the ARPA speech project. One can find similar statements by Cuic and Jakimik (CiMU) [5] and by Jelinek (JBM) [17].

I prefer to think of variation as useful. It is wcll known that allophonic contrasts can be distinctive, as illustrated by the following famous minimal pairs where the crucial distinctions scem to lic in the allophonic realization of the $/ \mathrm{U}$ :
(2a) a țease / aţ ease
(2b) night ratc / nițrate
(2c) grea! winc / gray !wine
aspirated / fapped unrelcased / retroflexed unreleased / rounded

This evidence suggests that alluphonic variation provides a tich source of constraints on syllable structure and word suress. The recognizer to be discussed here (and partly implemented in Church [ $[4]$ is designed to exploit allophonic and phonotactic cues by parsing the input utterance into syllables and other suprasegmental constituents using phrasestructure parsing techniques.

\subsection{An Example of Lexical Retricyal}

It might be helpful to work out an example in order to illustrate how parsing can play a role in lexical retricval. Consider the phonetic transcription, mentioned above in the citation from Klatt [20, p. 1346] [2], pp. 548-549]: 


\section{(3) [unghlclutum)}

It is desired to decude (3) into the string of words:

\section{(4) Did you hit it to Tom?}

In practice, the lexical retrieval problem is eomplicated by errors in the frome end. However, even with an ideal error-free front-end, it is difficult to decode (3) because, among other things, there arc cxtensive rulc-governed changes affecting the way that words are pronounced in different sentence contexts, as Klatt's example illustrates:

(5a) Palatalization of $/ \mathrm{J} /$ beforc $/ \mathrm{y} /$ in did you

(5b) Reduction of unstressed / $u$ / to schwa in $y q u$

(5c) Flapping of intervocalic $/ V$ in hit it

(5d) Reduction of schwa and devoicing of $/ u /$ in $l Q$

(5e) Reduction of geminate $/ v$ in it to

These allophonic processes often appear to neutralize phonemic distinctions. For example, the voicing contrast between $/ U$ and $/ d /$, which is usually distinctive, is almost completcly lost in writer/rider. where both $/ \mathrm{t} /$ and $/ \mathrm{d} /$ are realized in American English with a tongue flap [C].

\subsection{In Optimistic View of Neutralization}

Fortunatcly, there are many fewer cases of true neutralization than it might scern. Even in writer/rider, the voicing contrast is not completely lost. The vowel in rider tends to be longer than the vowel in writer duc to a gencral process that lengthens vowels before voiced consonants (c.g.. /d/) and shortens them before unvoiced consonants (c.g., / $/$ )

A similar lengthening urgument can be used to separate $/ \mathrm{n} /$ and fidd (at least in some cases). It inight be suggested that $/ \mathrm{n} /$ is merged with /nd/ by a /d/ delecion rule that applics in words like mend wind (noun). wind (:crb). and find. ( $\wedge$ dmittedly there is little if any direct acoustic evidence for a /d/ segment in this environment.) However, I suspect that these words can otten be distinguished from men, win wine. and fime mostly on the basis of the duration of the nasal murmur which is lengthened in the precedence of a voiced obstruent like $/ \mathrm{d} /$. Thus, this $/ d /$-detction process is probably not a true case of ncutralization.

Recent studics in acoustic/phonetics secm to indicate that more and more cases of apparent neutralization can be separated as the field progresscs. For instance, it has been said that $/ \mathrm{s} /$ merges with $/ \mathrm{s} /$ in a context like gas shomtage [12!. However, a recent experiment [27] suggests that the /š̃/ scquence can be distinguished from /šš/ (as in fish shortage) on the basis of a spectral tilt: the $/ s \bar{s} /$ spectrum is more

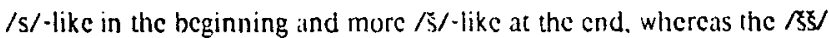
spectrum is relatively constant throughout. A similar spectral tilt argument can be used to separatc other cascs of apparent gemination (c.g., $/ 7 \delta /$ in is $($ he).

As a final example of apparent neutralization, consider the portion of the spectrogram in figure 1 between 0.85 and 1.1 seconds. This corresponds to the two adjacent / $/ \mathrm{s}$ in Did jou hit it lo Tom? Klatt analyzed this icgion with a single geminated / $/$. However, upon further investigation of the spectrum, I believe that there are acoustic cues for two segments. Note especially the total energy, which displays two peaks at 0.95 and 1.02 seconds. On the basis of this eyidence, I will replace Klatt's transcription (6a) with (6b):

\section{(6a) [drjahl[Its tam] \\ (6b) [d]jahtCIt titam] \\ $\lceil\uparrow$}

\subsection{Parsing and Matching}

Even though 1 might be able to re-interpret many cases of apparent neutralization. it remains extremely difficult to "undo" the allophonic rules by inverse transformational parsing techniques. Let me suggest an alternative proposal. I will treat syllable structure as an internediate level of representation between the input segment lattice and the output word lattice. In so doing, I have replaced the lexical retrieval probiem with two (hopefully simpler) problems: (a) parse the scgment lattice into syllable structure, and (b) match the resuiting constituents against the lexicon. I will illustrate the approach with

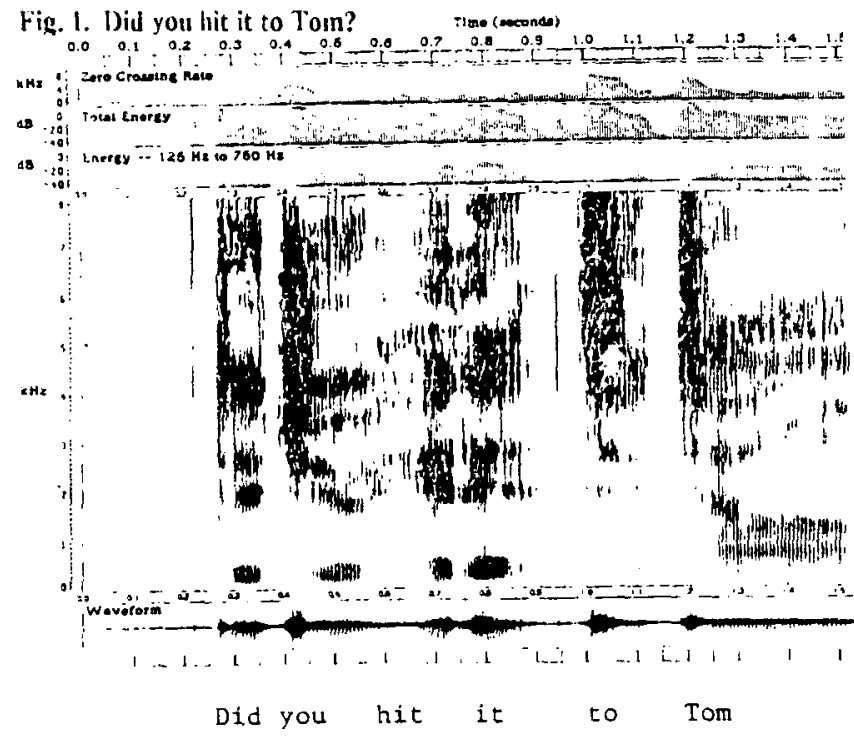


Klatt's example (enhanced with allophonic diacritics to show aspiration and glottalization):

(7) [d $\left[\mathrm{j} \partial \mathrm{hl}\left[\mathrm{I} ? \mathrm{t}^{\mathrm{h}} \mathrm{h}_{\mathrm{ft}} \mathrm{h}_{\mathrm{am}} \mathrm{am}\right.\right.$ it $\uparrow$

Using phonotactic and allophonic constraints on syilable structure such as: ${ }^{3}$

(8a) $/ \mathrm{h} /$ is always syllable initial.

phonolactic

(8b) [C] is always syllabie final.

allophonic

(8c) [?] is always syllable final, and

allophonic

(8d) $\left[t^{\mathrm{h}}\right]$ is always syllable initial.

allophonic

the parser can insert the following syllable boundaries:

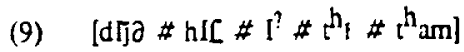

It is now it is relatively easy to decode the utterance with lexical matching routines similar to those in Smith's Noah program at CMU [24].

$\begin{array}{lll}\text { Darscd transcription } & & \text { dccoding } \\ \text { dija } & \rightarrow & \text { did you } \\ \text { hi[ } & \rightarrow & \text { hit } \\ \mathrm{I}^{?} & \rightarrow & \text { it } \\ \mathrm{h}_{\mathrm{l}} & \rightarrow & \text { to } \\ \mathrm{t}_{\mathrm{am}} & \rightarrow & \text { Tom }\end{array}$

In summary. I believe that the lexical retricval device will be in a superior position to hypothesize word candidates if it cxploits allophonic and phonotactic constraints on syilable structure.

\subsection{Exploiting Redundancy}

In many cases, allophonic and phonotactic constraints are redundant. Even if the parser should miss a few of the cues for syllabie structure. it will often be able to find the correct structure by luking advantage of some other redundant cue. For example, suppose that the front end failed to notice the glottalized $/ U$ in the word $i t$.

(10)

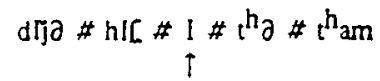

The parser could deduce that the input transcription (10) is internally inconsistent, because of a phonotactic constraint on the lax vowel /I/.

3. This formulation of the consuraints is oversimplified for expository convenience; see [10. 13.15] and retcrences therein for discussion of the more subtle issues.
L_ax vowels are restricted to çlosed syilables (syllibles cnding in a consonant) [1]. Howcrer, in this casc, // cannot mect the closed syllable restriction becausc the following consonant is aspirated (and therefore syllable initia). Thus the transcription is internally inconsistent. The parser should probably reject the transcrintion and hope that the front end can fix the problem. Alternatively, the parser might attempt to correct the error by hypothesizing a second $/ t .^{4}$

There are many other examples like (10) where phonotactic constraints and allophonic constraints overlap. Cunsider the pairs found in figure 2, where there are multiple arguments for assigning the crucial syllable boundary. In de-prive vs. dep-rivation, for instancc, the difference is revealed by the vowel argument above ${ }^{5}$ and by the aspiration rule. ${ }^{6}$ In addition, the stress contrast will probably be correlated with a number of so-called 'suprasegmental' cues, e.g., duration, fundamental frequency, and intensity [8].

In general, there seem to be a large number of multiple low level cues for syllable structure. This observation, if correct, could be viewed as a form of a 'constituency hypothesis'. Just as syntacticians have argued for the constituent-hood of noun phrases, verb phrases and sentences on the grounds that these constituents seem to capture crucial linguistic generalizations (c.g., question formation, wh-movement), so too, I might argue (along with certain phonologists such as Kahn [13]) that syllables, onscts, and rhymes are constituents because they also capture important generalizations such as aspiration, tensing and laxing. If this constituency hypothesis for phonology is correct (and I believe

Fig. 2. Some Structural Contrasts

\begin{tabular}{|c|c|c|c|}
\hline & 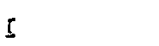 & 1 & $\underline{w}$ \\
\hline$\underline{\mathrm{g}}$ & $\begin{array}{l}\text { de-prive } \\
\text { dep-rivation }\end{array}$ & $\begin{array}{l}\text { di-plomacy } \\
\text { dip-lomatic }\end{array}$ & \\
\hline I & $\begin{array}{l}\text { a-tribute } \\
\text { att-ribute }\end{array}$ & & \\
\hline $\mathrm{k}$ & $\begin{array}{l}\text { de-crease } \\
\text { dec-riment }\end{array}$ & $\begin{array}{l}\text { de-cline } \\
\text { dec-lination }\end{array}$ & $\begin{array}{l}\text { a-cquire } \\
\text { acq-uisition }\end{array}$ \\
\hline$\underline{b}$ & $\begin{array}{l}\text { celc-bration } \\
\text { celcb-rity }\end{array}$ & $\begin{array}{l}\text { o-bligatory } \\
\text { ob-ligation }\end{array}$ & \\
\hline$\underline{\mathrm{d}}$ & $\begin{array}{l}\text { a-ddress } \\
\text { add-ress }\end{array}$ & & \\
\hline $\mathrm{g}$ & $\begin{array}{l}\text { de-grade } \\
\text { deg-radation }\end{array}$ & & \\
\hline
\end{tabular}

4. Personally, I favor the first alternative: anter years of witnessing Victor 7.ue read spectrograms. I have become most impressed with une nehness of low letel phonetic cues. 5 . The syllable de is upen because the vowel is tense (diphthongized); dep is closed because the vowel is lax

6. The $/ p /$ in -prive is syllable inilaal because it is aspirated whereas the $/ p /$ in dep is syllable final because it is unaspirated. 
thill it is). then it secens natural to propose a syllable parser for processing specch, by analogy with sentence parsers that have become stanciard practice in the natural language community for processing text.

\section{Parser Implementation and Feature Spreading}

A program has been implemented [4] which parses a lattice of phonetic segments into a lattice of syllables and other phonological constituents. Except for its novel mechanism for handling features, it is very much like a standard chart parser (e.g., Earley's Algorithm [7]). Recall that a chart parser takes as input a sentence and a context-free grammar and produces as output a chart like that below, indicating the starting point and ending point of each phrase in the input string.

Inpur Sencence: 0 They 1 are $2^{\text {nying }}$ $^{\text {planes }} 4$

Grammar:

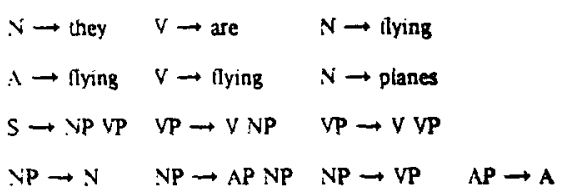

Chart:

\begin{tabular}{|c|c|c|c|c|c|}
\hline & 0 & 1 & 2 & 3 & 1 \\
\hline 0 & \{\} & $\{$ NP.N, they\} & $\{\mathbf{S}\}$ & $\{\mathrm{S}\}$ & $\{\mathbf{S}\}$ \\
\hline 1 & \{\} & \{\} & \{VP.V.are\} & $\{V P\}$ & $\{V P\}$ \\
\hline 2 & \{\} & \{\} & \{\} & $\{$ NP, $, P, A P, N, Y, A$, , Iying $\}$ & $\{N P . V P\}$ \\
\hline 3 & \{\} & \{\} & \{\} & \{\} & \{NP.N.planes\} \\
\hline+1 & \{\} & \{\} & \{\} & \{\} & (1) \\
\hline
\end{tabular}

Each entry in the chart represents the possible analyses of the input words beween a start position (the row index) and a finish position (the column index). For example, the entry $\{N P, V P\}$ in Chan $(2,4)$ represents two ditcrnative analyses of the words between 2 and 4: $\left[\mathrm{Xp}_{\mathrm{p}}\right.$ flymg pianes] and (vp $_{\mathrm{vp}}$ flying planes].

The same parsing methods can be used to find syllable structure from an input transcription.

innut Scntence: ${ }_{0} \mathrm{~J}_{1} t_{2} \mathrm{~s}_{3} \mathrm{I}_{4} \mathrm{z}_{5}$ (this is)

Grammar:

onset $\rightarrow 5|s| z$ peak $\rightarrow 111$

$\operatorname{cod} 3 \rightarrow \delta|s| z$ syl $\rightarrow$ (onsct) peak (coda)

\begin{tabular}{|c|c|c|c|c|c|c|}
\hline & 10 & 1. & 2 & 3 & 4 & $s$ \\
\hline 0 & \{\} & $\{\tilde{\delta}$, onset,coda $\}$ & $\{$ syl\} & $\{$ syl\} & \{\} & \{\} \\
\hline 1 & \{\} & \{\} & $\{f$.pcak,syl\} & $\{s y 1\}$ & \{\} & \{\} \\
\hline 2 & (1) & \{\} & \{\} & $\{$ S. onset,coda\} & $\{$ syl\} & $\{$ syl $\}$ \\
\hline 3 & $1\}$ & \{\} & \{\} & \{\} & $\{1 . p c a k . s y l\}$ & $\{$ syl $\}$ \\
\hline 4 & \{\} & \{\} & \{\} & \{\} & \{\} & $\{z$, onset,coda\} \\
\hline s) & \{\} & \{\} & \{\} & \{\} & \{\} & \{\} \\
\hline
\end{tabular}

This chart shows that the input sentence can be decomposed into two syllables. one from 0 to 3 (this) and another one from 4 to 5 (is). Alternatively, the input sentence can be decomposed into [ $\delta$ [ ] [s[z]. In this way, standard chart parsing techniques can be adopted to process alluphonic and phonotactic constraints, if the constraints are reformulated in terms of a grammar.

How can allophonic and phonotactic constraints be cast in terms of context-frec rules? In many cases. the constraints can be carricd over in a straightforward way. For example, the following set of rules express the aspiration constraint discussed above. These rulcs allow aspiration in syllable initial position (under the onset node), but not in syllabie final position (under the coda).

(Ila) uttcrance $\rightarrow$ syllable*

(IIb) syllable $\rightarrow$ (onset) peak (coda)

(1lc) onset $\rightarrow$ aspirated $-\imath \mid$ aspirated $-k \mid$ aspirated $-p \mid \ldots$

(Ild) coda $\rightarrow$ unreleascd-t | unrelcased-k | unrcicased-p | ...

The aspiration constraint (as stated above) is relatively casy to cast in terms of context-frec rules. Other allophonic and phonotactic processes may be more difficult. ${ }^{7}$

\subsection{The Agreement Problem}

In particular, context-free rules are gencrally considered to be awkward for expressing agreement facts. For example, in order to express subject-verb agrcement in "pure" context-free rules, it is probably necessary to expand the rule $S \rightarrow$ NP VP into two cases:

(12a) $S \rightarrow$ singular-NP singular-VP

singular case

(12b) $\mathrm{S} \rightarrow$ plural-NP plural-VP

plural case

7. For example. there may be a problem with constraints that depend on rule ordering. since rule ordering is not supponed in the context-free formalism. This topic is diseussed at length in $[4]$ 
The agreement problem also arises in phonology. Consider the example of homorganic nasal clusters (c.g., camb can'l sank), where the nasal agrees with the following obstrient in piace of articulation. That is, the labial nasal $/ \mathrm{m} /$ is found before the labial stop $/ \mathrm{p} /$, the coronal nasal $/ n /$ before the coronal stop $/ t /$, and the velar nasal $/ \eta /$ before the velar stop $/ \mathrm{k} /$. This constraint, like subject-verb agreement, poses a problem for pure unaugmented context-free rules; it seems to be necessary to expand out cach of the three cases:

(13a) homorganic-nasal-cluster $\rightarrow$ labial-nasal labial-obstruent

(13b) homorganic-nasal-cluster $\rightarrow$ coronal-nasal coronal-obstruent

(13c) homorganic-nasal-cluster $\rightarrow$ velar-nasal velar-obstruent

In an effort to alleviate this expansion problem, many researchers have proposed augmentations of various sorts (e.g., $A T \mathrm{~N}$ registers [26]. LFG constraint equations [16], GPSG meta-rules [11], local constraints [18]. bit vectors $[6,22])$. My own solution will be suggested after ( have had a chance to describe the parser in further detail.

\subsection{Parser Based on Watrix Operations}

This scction will show how the grammar can be implemented in terms of opcrations on binary matrices. Suppose that the chare is dccomposed into a sum of binary matrices:

(14) $\quad$ Chart $=$ syl $M_{\text {syl }}+$ onset $M_{\text {onset }}+$ pcak $M_{\text {peak }}+\ldots$

where $M_{\text {syl }}$ is a binary matrix ${ }^{8}$ describing the location of syilables and $M_{\text {onset }}$ is a binary macrix describing the location of onsets, and so forth. Each of these binary matrices has a $l$ in position $(i, j)$ if there is a cunstituent of the appropriate part of specch spanning from the $i^{\text {th }}$ position in the input sentence to the $j^{\text {th }}$ position. ${ }^{9}$ (Sce figure 3).

Phirase-structure rulcs will be impiemented with simple operations on these binary matrices. For example. the homorganic rule (13) could be implemented as:

8. These matnces will sometimes be called segmentation latices for historical reasons. Technically. these matnees necd not con iorm to the restructions of a lattice, and therefore. the weaker term graph is more correct

9 In a probabilisuc framework. onc could replace all of the i's and 0 's with probabilities. A high probability in location (i. ) of the syllable matrix would say that there probably is a syllable from position t 10 position $f:$ a low probability would say that there probabiy isn't a syllable between $i$ and $f$. Most of the following applics to probability matrices as well as binary matrices. though the probability matnces may be less sparse and conscquently less efficient.
Figg. 3. $M_{\text {syil }}, M_{\text {onsel }}$ and $M_{\text {rhyme }}$ for: $*_{0} \delta_{1} t_{2} s_{3} l_{4} \%_{5} "$

\begin{tabular}{|c|c|c|}
\hline 0011100 & 010000 & 0000000 \\
\hline 001100 & 000000 & 001100 \\
\hline 0000011 & 0001100 & 00000000 \\
\hline 00000011 & $\begin{array}{lllllll}0 & 0 & 0 & 0 & 0 & 1\end{array}$ & 0000011 \\
\hline 000000 & 000000 & 000000 \\
\hline 000000 & $\begin{array}{lllllll}0 & 0 & 0 & 0 & 0 & 0\end{array}$ & $\begin{array}{llllll}0 & 0 & 0 & 0 & 0 & 0\end{array}$ \\
\hline
\end{tabular}

The matrices tend to be very sparse (almost entirely full of 0 's) because syllable grammars are highly constrained. In principle, there could be $\mathrm{n}^{2}$ entries. However, it can be shown that e (the number of l's) is lincarly related to $n$ because syllables have finite length. In Church [4], I sharpen this result by arguing that $e$ tends to be bounded by $4 n$ as a consequence of a phonotactic principle known as sonority. Many more edges will be ruled out by a number of other linguistic constraints mentioned above: voicing and place assimilation, aspiration, flapping, etc. In short, these matrices are sparse because allophonic and phonotactic constraints are useful.

(15)

(setq homorganic-nasal-lattice

$(\mathrm{M}+(\mathrm{M} *$ (phoneme-lattice $\# / \mathrm{m})$ labial-lattice)

(M* (phoneme-lattice $\# / n$ ) coronal-lattice)

$(M *($ phoneme-lattice $\# / G)$ velar-lattice)))

illustrating the use of $\mathrm{Y}+($ matrix addition) we express the union of several alternatives and $M *$ (matrix multiplication) to express the concatenation of subparts. It is well known that any finitc-state grammar could be implemented in this way with just three matrix opcrations: $M *, M+$, and $M^{* *}$ (transitive closure). If context-free power were required. Valient's algoridm [25] could be cmployed. However, since there doesn't secm to be a need for additional generative capacity in specch applications, the system is restricted to handle oniy the simpier finite stare case. ${ }^{10}$

\subsection{Feature Manipulation}

Although "pure" unaugmented finite stace grammars may be adequate for specch applications (in the weak gencrative capacity sense), I may, nevertheless, wish to introduce additional mechanism in order to account for agrecment facts in a natural way. As discussed above, the formulation of the homorganic rule in (15) is unattractive becausc it splits the rule into three cases, one for each place of articulation. It would be preferable to state the agrecment constraint just once, by defining a homorganic nasal cluster to be a nasal cluster

10. I personally hold a much more controversial position. that finite statc grammars are sufficient for most if not all, natural language tasks [3]. 
subject to place assimilation. In my language of mattix operations, I can say just exactly that:

(16) (sctq homorganic-nasal-clustcr-lattice

$$
\begin{array}{r}
\text { (M\& nasal-cluster-lattice } \\
\text { placc-assimilation)) }
\end{array}
$$

where M\& (element-wise intersection) implements the subject to constraint. Nasal-cluster and placc-assimilation are defined as:

(17a) (setq nasal-clustcr-lattice

(M* nasal-lattice obstruent-lattice))

(17b) (setq place-assimilation-lattice

$$
\begin{array}{r}
\left(\mathrm{M}+\left(\mathrm{M}^{* *} \text { labial-lattice }\right)\right. \\
\left(\mathrm{M}^{* *} \text { dental-lattice }\right) \\
\left.\left.\left(\mathrm{M}^{* *} \text { velar-lattice }\right)\right)\right)
\end{array}
$$

In this way, M\& seems to be an attractive solution to the agrecment problem.

In addition, M\& might also shed some light on co-articulation. another problem of 'feature spreading'. Co-articulation (articulation of multiple phonemes at the same time) makes it extremely difficult (perhaps impossible) to segment the speech waveform into phoncme-

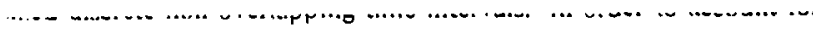
co-articulation, Fujimura suggests that place, manner and other articuiatory features be thought of as asynchronous processes, which have a certain anount of freedum to ovcrlap in time.

(18a) "Speech is commonly viewed as the result of concatenating phonctic segments. In most discussions of the temporal structure of specch, a segment in such a model is assumed to represent a phoneme-sized phonetic unic which possesses an inherent [invariant] target value in terms of articulation or acoustic manifestation. Any deviation from such an interpretation of observed phenomena requires special attention ... [B]ased on some preliminary results of $\mathrm{X}$-ray microbeam studics [which assocjate lip. tongue and jaw movements with phonetic events in the uttcrancel, it will be suggested that understanding articulatory processes. which are inherently multi-dimensional [and (more or less) asynchronous], may be essenual for a successful description of temporal suructures of specch." $[9$ p. 66]

In light of Fijimura's suggestion. I might re-interpret my parser as a highly parallel feature-based asynchronous architccture. For example. the parser can process homorganic nasal clusters by processing place and manner phrases in parallel, and then synchronizing the results at the coda node with M\&. That is, (17a) can be computed in parallel with (17b), and then the resuits are aligned when the coda is computed with (16). as illustrated below for the word tent. Imagine that the front end produces the following analysis:

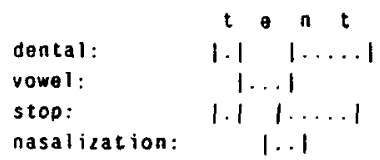

where many of the features overlap in an asynchronous way. The parser will correctly locate the coda by intersecting the nasal cluster lattice (computed with (17a)) with the homorganic lattice (computed with (17b)).

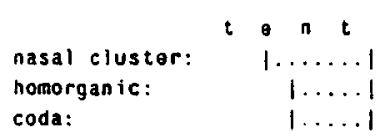

This parser is a bold departure from a standard practice in two respects: (1) the input stream is feature-based rather than scgmental, and (2) the output parse is a hetcrarchy of overiapping constituents (c.g., place and manner phrases) as opposed to a list of hicrarchical parse-trees. I find thesc two modifications most exciting and worthy of further investigation.

In summary, (wo) points bave been Inade. First. I suggested the usc of parsing techniques at the segmental/feature level in speech applications. Secondly, I introduced $M \&$ as a possible sulution to the agrecinent/co-articulation problem.

\section{Acknowledgements}

I have received a considerable amount of help and support over the course of this project. Let me mention just a few of the peuple that I should thank: Jon Allen. Glenn Burke. Francine Chen, Scout Cyphers, Sarah Ferguson, Margaret Fleck, Dan Hiuttenlocher, Jay Keyser. Lori Lamel. Ramesh Patil, Janet Picrrehumbert. Dave Shipman. Pcte Szulovits. Meg Withgott and Victor Zue.

\section{References}

1. Barnwell, T., an Algorthm for Segnent Durations in a Reading Machine Context, unpublished doctoral dissertation, department of Electrical Enginecring and Computer Science, MIT, 1970.

2. Chomsky. N. and Halle. M., The Sound Pattern of English, Harper \& Row, 1968.

3. Church, K., On Memon Limitations in Natural Language Processing. MS Thesis, MIT, MIT/L.CS/lR-245, 1980 (also availabie from Indiana University Linguistics Club). 
4. Church, K., Phrase-Sirncture l'arsing: A Method for Taking Advanage of Allophonic Constraints, unpublished doctoral dissertation, departınent of Flectrical Fingincering and Computer Science, MIT', 1983 (also to appear, L.CS and RLE publications, MIT).

5. Culc. R., and Jakimik, J., A Model of Speech Perception, in R. Cole (ed.), Perception and Production of Fluent Speech, Lawrence Eribaum, Hillsdale, N.J., 1980.

6. Dustert, B., and Thompson, F., How Features Resolve Syntactic Ambiguity, in Proceedings of the Symposium on Information Storage and Retrieval, Minker. J., and Rosenfeid, S. (cd.), 1971.

7. Earley, J., An Efficient Context-Free Parsing Algorithm, CACM, 13:2, Fcbruary, 1970.

8. Fry, D., Duration and Intensity as Physical Correlates of Linguistic Siress, JASA 17:4, 1955, (reprinted in Lchiste (ed.). Readings in Acoustic Phonetics, MI'T Press, 1967.)

9. Fujimura, O., Temporal Organization of Articulatory Moveinents as Multidimensional Phrasal Structure, Phonctica, 33: pp. 66-83, 1981.

10. Fujimura, O., and Lovins. J., Syllables as Concatenative Phonetic Unts. Indiana University Linguistics Club, 1982.

11. Gazdar. G.. Phrase Structure Granmar, in P. Jacobson and G. Pullum (eds.). The Nature of Syntactic Representation. D. Reidel, Dordrecht, in press, 1982.

12. Heffner, R. General Phonetics, The University of Wisconsin Press, 1960.

13. Kahn. D., Syllable-Based (ieneralizations in linglish Phonology. Indiana University Linguistics Club, 1976.

14. Kiparsky, P.. Remarks on the Hetrical Siructure of the Syllable. in W. Dressler (cd.) Phonologica 1980. Proceedings of the Fourih International Phonology Meeting, 1981.

15. Kiparsky. P.. Metrical Siructure Assigmments in Cyclic. l.inguistic Inquiry, 10, pp. 421-441, 1979.

16. Kaplan, R. and Bresnan, J., Lexicat-Functional Grammar: A Formal System for Grammatical Representation, in Bresnan (ed.). The Mcntal Representation of Grammatical Relations, MI'T Press. 1982.

17. Jelinck, F., course notes, MIT, 1982.

18. Jushi, A., and I.evy, L.. Phrase Structure Trees Bear More Fruit Than You Would Have Thought, AJCL, 8:I, 1982.

19. Klatt. D. Word Verification in a Speech Understanding System, in R. Reddy (ed.), Speech Recognition, Inviced Papers Presented at the 1974 IF.EE Symposium. Academic Press, pp. 321-344, 1974.

20. Klath, D., Review of the ARPA Speech Understanding Project. JASA. 62:6. Deccmber 1977.

21. Klatt. D., Scriber and Lafs: Two New Approaches to Speech Analysis, chapter 25 in W. Lea, Trends in Speech Recogmition, Prentice-Hall, 1980.

22. Martin. W., Church, K., and Patil, R., Preliminary Analysis of a Breadih-First larsing Alyorithm: Theoretical and Expermemlal Results. MIT/LCS/TR-261. 1981 (also to appear in 1.. Bolc (cd.), Nolural language Parsing Systems. Macmillan, L.ondon).
23. Reddy, R., Speech Recognition by Machine: i Review, Procecdings of the IIEE, pp. 501-531, April 1976.

24. Sinith, $\Lambda$., Word Hypothesization in the Hearsay-l/ Speech System, Proc. IEEF. Int. Conf. ASSP, pp. 549-552, 1976.

25. Valient, L., General Context Free Recognition in Less Than Cubic Time, J. Computer and System Sciences 10, pp. 308 315. 1975.

26. Woods, W., Transition Network Grammars for Natural Language Analysis. CACM, 13:10, 1970.

27. Zuc, V., and Shatuck-Hufnagel, S. When is a $\&$ not $a$ $\Re ?$, ASA, Atlanta, 1980. 